\title{
Validation of Competitive Ability of Diverse Canola Accessions against Annual Ryegrass under Glasshouse and Field Conditions
}

\author{
Nawar Shamaya',2, Harsh Raman ${ }^{1,2 *}$, Maheswaran Rohan1, Jim Pratley², Hanwen Wu1,2 \\ ${ }^{1}$ NSW Department of Primary Industries, Wagga Wagga Agricultural Institute, PMB, Wagga Wagga, NSW, Australia \\ ${ }^{2}$ Graham Centre for Agricultural Innovation, Charles Sturt University, Wagga Wagga, NSW, Australia \\ Email: ${ }^{\star}$ arsh.raman@dpi.nsw.gov.au
}

How to cite this paper: Shamaya, N., Raman, H., Rohan, M., Pratley, J. and Wu, H.W. (2020) Validation of Competitive Ability of Diverse Canola Accessions against Annual Ryegrass under Glasshouse and Field Conditions. Open Journal of Genetics, 10 , 17-34.

https://doi.org/10.4236/ojgen.2020.102003

Received: January 10, 2020

Accepted: March 8, 2020

Published: March 11, 2020

Copyright $\odot 2020$ by author(s) and Scientific Research Publishing Inc. This work is licensed under the Creative Commons Attribution International License (CC BY 4.0).

http://creativecommons.org/licenses/by/4.0/

\begin{abstract}
Weeds are a major constraint in canola (Brassica napus L.) production worldwide, as they cause significant reductions in seed yield and quality. Crop interference is one of the approaches to tackle weed infestation along with other agronomic interventions. In Australia, studies have shown genetic variation in the canola capability to suppress annual ryegrass (Lolium rigidum Gaudin) in the field and under in vitro conditions. Early-season crop biomass accumulation and greater plant height are desired attributes for suppression weeds in canola. However, the canola ideotype for interference traits against this weed has not been studied under glasshouse conditions. In this study, we compared the competitive ability of 26 canola genotypes against annual ryegrass under both glasshouse and field conditions. Five canola genotypes consistently showed the ability to suppress growth of annual ryegrass. Both at glasshouse and field conditions, the shoot biomass, largely contributed by leaf biomass, was significantly associated with suppression ability. Our results suggest that a glasshouse-based evaluation approach can be used to determine the suppressive ability of advanced breeding lines for suppression of ryegrass growth. Based on our analysis, we suggest that initial screening of large collections of germplasm can be conducted under glasshouse conditions, with selected genotypes further evaluated in the field.
\end{abstract}

\section{Keywords}

Brassica napus, Weed-Crop Competition, Crop Interference, Ideotype

\section{Introduction}

Canola (Brassica napus L.) is an important oilseed crop grown worldwide. In 
recent years, canola cultivation has expanded rapidly due to its high grain prices and demand for healthy vegetable oil, stockfeed and biodiesel markets [1]. Weed infestation, however, is a major constraint limiting canola production [2]. In Australia, total yield loss due to weeds in canola and pulses has been estimated at 122,048 tonnes, resulting in a revenue loss of $\$ 54$ million [3]. Annual ryegrass (Lolium rigidum Gaudin) has been the most widespread weed in winter crops, occurring in $86 \%$ of canola crops in south-eastern Australia [2].

The primary method of weed control is the application of herbicides. However, the prolonged and widespread chemical use has been increased especially after the introduction of herbicide-tolerant cultivars to triazine, imidazolinone and glyphosate. This has led to an increase in the evolution of herbicide resistance [4]. Canola seems to be particularly vulnerable for developing to herbicide resistance as there are limited options of commercial herbicide available to control broad-leaf weeds. In recent years, the canola industry is increasingly becoming dependent on herbicide tolerant varieties including genetically modified herbicide tolerant varieties, which are meant to provide control options for the major weeds of that crop, such as annual ryegrass and wild radish (Raphanus raphanistrum). Evaluation of the herbicides against different weed species showed that 8 of the top 15 are likely to be utilised in canola production, including imazamox and imazethapyr for the Clearfield ${ }^{\oplus} \mathrm{HR}$ canola, glyphosate for the Roundup Ready ${ }^{\oplus}$ canola, and atrazine and simazine for the triazine tolerant lines are resistant to herbicides [5]. In recent years, some countries are imposing restriction on the usage of certain herbicides such as glyphosate for weed control; this practice necessitates the development of alternative and sustainable options for weed management. In addition to agronomic interventions that can influence weed management including seeding rate, row spacing, row orientation and fertilizer [6] [7], crop interference is worth investigating as a tool for weed management [8]-[14]. Considerable genotypic variation for weed competition exists in crop plants including canola, although some species are considered more competitive than others [15] [16] [17] [18]. For example, studies have shown canola to be less competitive on weeds than wheat and barley [19] [20] [21]. Vigorous hybrid canola varieties were found to be more competitive than open-pollinated varieties, largely attributed to greater hybrid vigour traits such as plant height and early-season crop biomass accumulation [9] [22] [23] [24] [25]. The competitive ability of a crop to weeds can be measured either on the basis of the ability of crop to maintain growth and seed yield in the presence of weed, or on the basis of the ability of crop to suppress growth and seed production of weed species [26]. Weed competitiveness in canola has been evaluated mainly under laboratory and field conditions and to a limited extent under glasshouse conditions [9] [27] [28]. Under field conditions, it is difficult to achieve precise and uniform plant densities across a trial site, and this may influence the differential responses obtained [26] [29]. Secondly, field conditions can compromise the outcomes through environmental variance [9] [26] [30]. Lastly, screening large 
numbers of genotypes for weed-crop competition under field conditions is labour and space intensive [31].

The objective of this study is to evaluate the suppression ability of different canola genotypes against ryegrass. Obtaining reliable estimates of weed competitive ability and understanding the canola ideotype for interference traits are important for designing sustainable weed control strategies with low herbicide use for improving canola productivity and profitability.

\section{Materials and Methods}

\subsection{Canola Genotype and Weed Populations}

Previously, Asaduzzaman et al. [27] utilised 70 genotypes of canola to investigate genotypic variation for allelopathy and weed competitiveness. In this study, a set of 26 diverse Brassica genotypes (Table 1), including a subset of canola genotypes utilised by Asaduzzaman et al. [8] was characterised for their competitive ability against annual ryegrass cv. Wimmera under glasshouse and field conditions. This rye grass cultivar is well-suited to dry and low fertile soils and extensively used for productive, nutritious pasture crop. Seeds of canola genotypes were accessed from the National Brassica Germplasm Improvement Program (Wagga Wagga, Australia).

\subsection{Evaluation of Canola-Weed Suppressive Ability under Glasshouse Conditions}

The glasshouse experiment was conducted at the Wagga Wagga Agricultural Institute, NSW, Australia. The experiment was arranged in split-plot design with three replicates; main plots were 26 canola genotypes and subplots were the weed and weed-free treatments. Each experimental unit had four pots. The target canola density was five plants per pot in each treatment and ten annual ryegrass plants per pot in the weedy treatment. The 200 millimetre in diameter pots were filled with commercial garden mix containing: compost, manure, pine fines, sand and loam (3:3:2:1:1: by volume, $2 \mathrm{~kg} / \mathrm{pot})$. Fertiliser, $50 \mathrm{~mL} \cdot \mathrm{pot}^{-1}$ (22.23 $\mathrm{mL} \cdot \mathrm{L}^{-1}$ of water) of Thrive ${ }^{\mathrm{Tm}}(\mathrm{NPK}=25: 5: 8.8)$, was added once per week. When canola plants started flowering, magnesium sulphate $\left(2 \mathrm{~g} \cdot \mathrm{L}^{-1}\right.$ of water) was added once per week. Imidacloprid $\left(15 \mathrm{~g} \cdot \mathrm{L}^{-1}\right)$ was used against aphids as needed, and Prothioconazole and Tebuconazole $\left(210 \mathrm{~g} \cdot \mathrm{L}^{-1}\right)$ were used to control downy mildew disease as needed. The experiment was conducted under a $25 / 15^{\circ} \mathrm{C}$ day/night temperature regime with a 16 -h photoperiod. Pots were watered daily to field capacity, avoiding any confounding effect due to moisture stress. At $50 \mathrm{~d}$ after sowing, shoots of canola were cut at the soil level to estimate stem and leaf biomass. Numbers of leaves on the main stem were counted and then leaves were separated from the stem and placed in separate paper bags. Both leaves and stems were dried at $70^{\circ} \mathrm{C}$ for $48 \mathrm{~h}$, and weighed. The shoots of 10 annual ryegrass plants were harvested from each pot, dried at $70^{\circ} \mathrm{C}$ for $48 \mathrm{~h}$ and weighed. Plant height was measured from the soil level to the top of the 
Table 1. Phenology and country of origin of canola accessions.

\begin{tabular}{|c|c|c|}
\hline Genotype & Phenology & Country of origin \\
\hline PAK85388-502 & Semi-winter & Pakistan \\
\hline X6-06-3275-3 & Semi-winter & China \\
\hline Ningyou7 & Semi-winter & China \\
\hline Av-Opal & Spring & Australia \\
\hline Barossa & Spring & Australia \\
\hline ATR-409 & Spring & Australia \\
\hline Sturt-TT & Spring & Australia \\
\hline Hurricane & Spring & Australia \\
\hline Av-Garnet & Spring & Australia \\
\hline CB-Argyle & Spring & Australia \\
\hline RP04 & Spring & Australia \\
\hline Ag-Outback & Spring & Australia \\
\hline Skipton & Spring & Australia \\
\hline Ag-Spectrum & Spring & Australia \\
\hline BLN3343C001401 & Spring & Australia \\
\hline Rainbow & Spring & Australia \\
\hline Rivette & Spring & Australia \\
\hline ROY98310 & Spring & Australia \\
\hline Tarcoola-141 & Spring & Australia \\
\hline Lantern & Spring & Australia \\
\hline CB-Trigold & Spring & Australia \\
\hline Gross-Luesewitzer & Winter & Germany \\
\hline Tapidor & Winter & Germany/France \\
\hline Licapo & Winter & Germany \\
\hline Beluga & Winter & Italy \\
\hline Akela & Winter & Germany \\
\hline
\end{tabular}

canopy of the main (primary) stem.

\subsection{Evaluation of Canola-Weed Suppressive Ability in the Field}

The field experiments were conducted at the Wagga Wagga Agricultural Institute, Australia ( $35^{\circ} 30^{\prime} 07^{\prime \prime} S$; $147^{\circ} 21^{\prime} 06^{\prime \prime} 0 \mathrm{E}$ ) in a duplex Red Kandosol of pH 5.3. The field had a history of naturally high annual ryegrass population. Herbicides including glyphosate $\left(450 \mathrm{~g} \cdot \mathrm{L}^{-1}\right)$ and oxyfluorfen $\left(450 \mathrm{~g} \cdot \mathrm{L}^{-1}\right)$ were used to control annual ryegrass before sowing. Canola was sown on June 1, 2017 (due to unavailability of sufficient soil moisture during the main canola growing season i.e. late April to mid-May) with sowing rate of 1400 seeds plot $^{-1}$ and with 120 
$\mathrm{kg} \cdot \mathrm{ha}^{-1}$ of Croplift ${ }^{\text {tw }}$ fertiliser treated with fungicide (Flutriafol, $500 \mathrm{~g} \cdot \mathrm{L}^{-1}$ ). Urea $(46 \% \mathrm{~N})$ was applied twice at $75 \mathrm{~kg} \cdot \mathrm{ha}^{-1}$, at sowing time and in the canola vegetative phase. Foliar applications of Prothioconazole ${ }^{\bullet}$ and Tebuconazole ${ }^{\oplus}$ (210 $\mathrm{g} \cdot \mathrm{L}^{-1}$ ) against the fungal disease blackleg caused by Leptosphaeria maculans and Pirimicarb ${ }^{\circledast}\left(500 \mathrm{~g} \cdot \mathrm{kg}^{-1}\right)$ against aphids were applied as needed.

The experimental design was a complete randomised block with 26 genotypes (Sturt-TT was not included) and with three replicates in a spatially optimised layout of 5 ranges $\times 15$ rows. Plot size was $1.6 \mathrm{~m}$ wide by $8 \mathrm{~m}$ long with 6 rows at a row spacing of $22 \mathrm{~cm}$. On September 7, 2017 (100 days of sowing), canola and annual ryegrass densities were recorded in three random quadrats of $1 \mathrm{~m}$ by $1 \mathrm{~m}$ per plot. Canola biomass was determined from ten plants in the middle row of the plot whereas weed biomass was determined from three quadrats of $1 \mathrm{~m}$ by 1 $\mathrm{m}$ per plot. Both canola and weed biomass were cut at early canola flowering on September 20, 2017 and dried at $70^{\circ} \mathrm{C}$ for $48 \mathrm{~h}$. Plant height of canola was recorded twice in each plot by measuring the height of 10 randomly-selected plants per plot at early flowering and at crop maturity stages. The time of $50 \%$ canola flowering of each genotype was recorded (mid-September to mid-October). Plots were harvested at maturity with a small-plot header (Kingaroy, Australia) and grain yield was expressed in g lot $^{-1}$.

\section{Statistical Analysis}

Glasshouse trial: Data were analysed using $\mathrm{R}$ software [32] and the ASReml package [33]. Graphics were produced in the lattice package [34]. The typical ASReml mixed model employed had fixed effects for genotype, weed (weedy $\mathrm{v}$ weed-free), and their interaction. Random effects were included (where significantly different from zero) for main plots and subplots.

Field trial: A Shapiro-Wilk test was used to examine the data for normality and scatter plot of residual versus fitted value was used to assess the homoscedasticity. On confirming data normality, the ASReml package in R was used to perform a linear mixed effect model. The observed data for crop shoot biomass $\left(\mathrm{g} \mathrm{plot}^{-1}\right)$ and crop height $\left(\mathrm{cm}\right.$ plant $\left.{ }^{-1}\right)$ were normally distributed, whereas the data for yield $\left(\mathrm{g} \mathrm{plot}^{-1}\right.$ ) was transformed to obtain normal distribution. The Box-Cox transformation using the parameter lambda equal to 0.25 was used to transform yield data. The aim of the analysis was to examine both the genotype effects and weed biomass while accounting for the block stratification and spatial layout of the plots (including ryegrass density across plots). The mean with 95\% confidence interval for yield plot $^{-1}$, average crop height plot $^{-1}$ at flowering time and crop shoot biomass plot $^{-1}$ were presented graphically.

Correlation analysis: The Performance Analytics package in $\mathrm{R}$ was used for understanding their inter-relationships, including to describe their correlations in graphical format. The ggplot2 package in $\mathrm{R}$ was used to investigate the annual ryegrass response to 26 canola genotypes under the glasshouse and field conditions. 


\section{Results}

\subsection{Genetic Variation for Weedcompetitive Ability under Glasshouse Conditions}

The analysis revealed highly significant differences between genotypes and between weed treatments for all traits evaluated, whereas the interaction between the genotype and weed treatments was only significant in stem biomass and plant height (Table 2). Several genotypes revealed a strong ability to interfere with ryegrass growth under glasshouse conditions. Significant genotypic effects were found on shoot biomass of ryegrass that ranged from 1.05 to $2.28 \mathrm{~g} \mathrm{plant}^{-1}$ (Figure 1(a)). Two winter varieties (cv. Akela and cv. Gross-Luesewitze) and a semi-winter variety (cv. Ningyou 7) were the most ryegrass suppressive genotypes, resulting in a lower annual ryegrass biomass of 1.05 to $1.26 \mathrm{~g} \mathrm{plant}^{-1}$, followed by three Australian spring varieties (Av-Garnet, Av-Opal and Tarcoola-141). However, the other three Australian spring varieties (Sturt-TT, Ag-Spectrum and Lantern) were least suppressive, having higher levels of ryegrass biomass (2.15 to $2.28 \mathrm{~g} \mathrm{plant}^{-1}$ ). These results suggested that growth habit of canola genotypes does not have any consistent relationship with ryegrass suppression.

Weed treatment influenced shoot biomass of canola genotypes as compared with the weed-free treatment (Figure $1(\mathrm{c})$ ). However, the crop height was less affected by the presence of ryegrass (Figure $1(\mathrm{~b})$ ). This explains why crop biomass had higher negative correlation with weed biomass relative to the low correlation between crop height and ryegrass biomass. To identify competitive traits suitable for genetic selection, we sought correlation relationships between ryegrass and canola phenotypes. Leaf and shoot biomass showed a significant negative correlation ( $r=-0.50$ to -0.76 ) with biomass of annual ryegrass (Figure 2 ). In contrast crop heights and leaf number had positive relationships with ryegrass biomass (Figure 2).

\subsection{Validation of Genetic Variation for Weed Competitive Ability under Field Conditions}

Our glasshouse experiment revealed that vigorous canola genotypes having

Table 2. $P$-values for fixed effects (genotype, weed treatment and genotype $\mathrm{x}$ weed interaction for each six traits measured under the glasshouse condition.

\begin{tabular}{ccccccc}
\hline Effect & $\begin{array}{c}* \text { Dry weed } \\
\text { biomass } \\
\left(\mathrm{g} \mathrm{plant}^{-1}\right)\end{array}$ & $\begin{array}{c}\text { Dry shoot } \\
\text { biomass } \\
\left(\mathrm{g} \mathrm{plant}^{-1}\right)\end{array}$ & $\begin{array}{c}\text { Dry leaf } \\
\text { biomass } \\
\left(\mathrm{g} \mathrm{plant}^{-1}\right)\end{array}$ & $\begin{array}{c}\text { Dry stem } \\
\text { biomass } \\
\left(\mathrm{g} \mathrm{plant}^{-1}\right)\end{array}$ & $\begin{array}{c}\text { Leaf } \\
\left(\mathrm{no.} \mathrm{plant}^{-1}\right)\end{array}$ & $\begin{array}{c}\text { Plant height } \\
\left(\mathrm{cm} \mathrm{plant}^{-1}\right)\end{array}$ \\
\hline Genotype & $<0.001$ & $<0.001$ & $<0.001$ & $<0.001$ & $<0.001$ & $<0.001$ \\
Weed & $\mathrm{n} / \mathrm{a}$ & $<0.001$ & $<0.001$ & $<0.001$ & $<0.001$ & $<0.001$ \\
Interaction & $\mathrm{n} / \mathrm{a}$ & 0.211 & 0.64 & $<0.001$ & 0.624 & 0.001 \\
\hline
\end{tabular}

${ }^{*} \mathrm{n} / \mathrm{a}$, Not applicable; only weedy treatment are included in the analysis of weed biomass. 

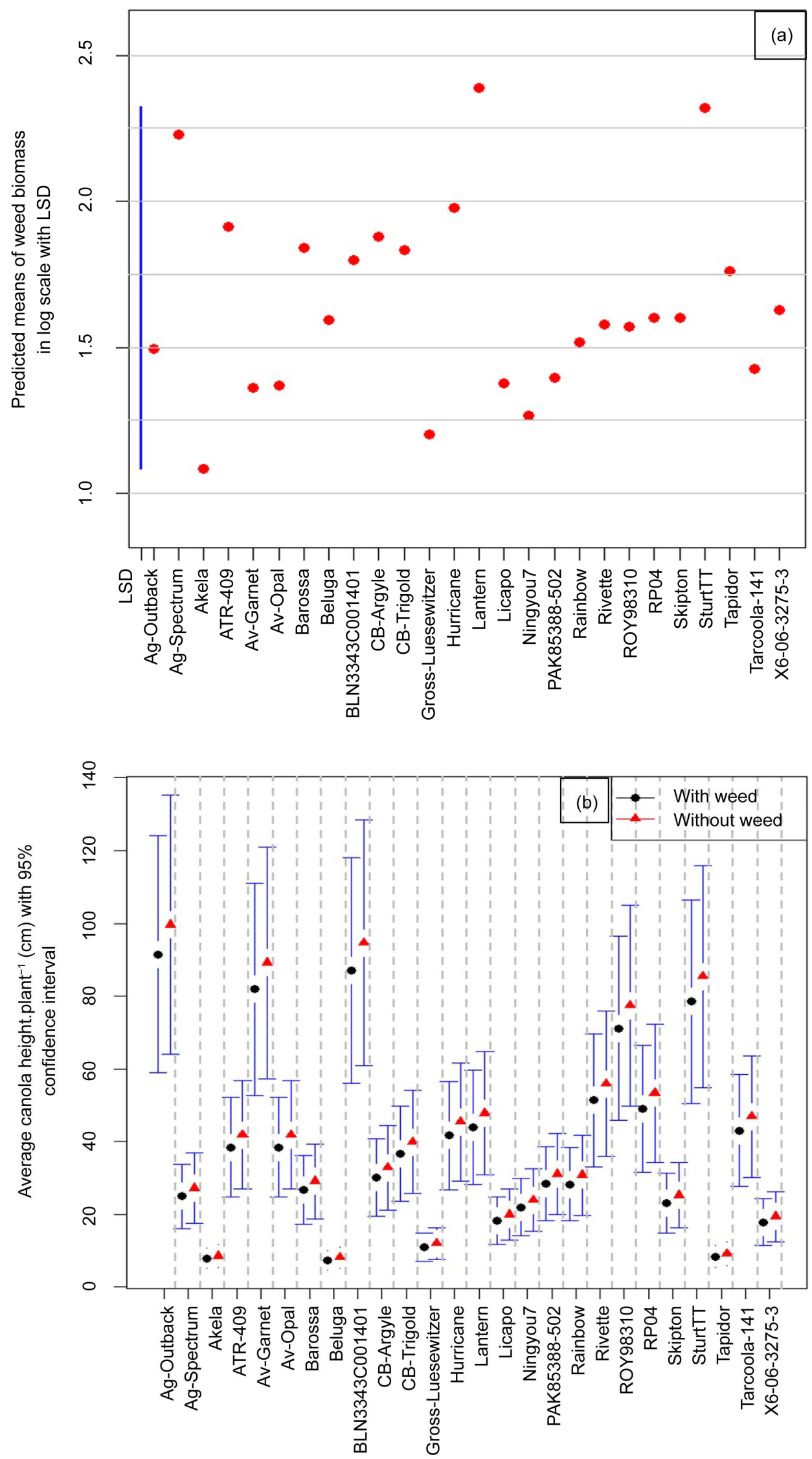

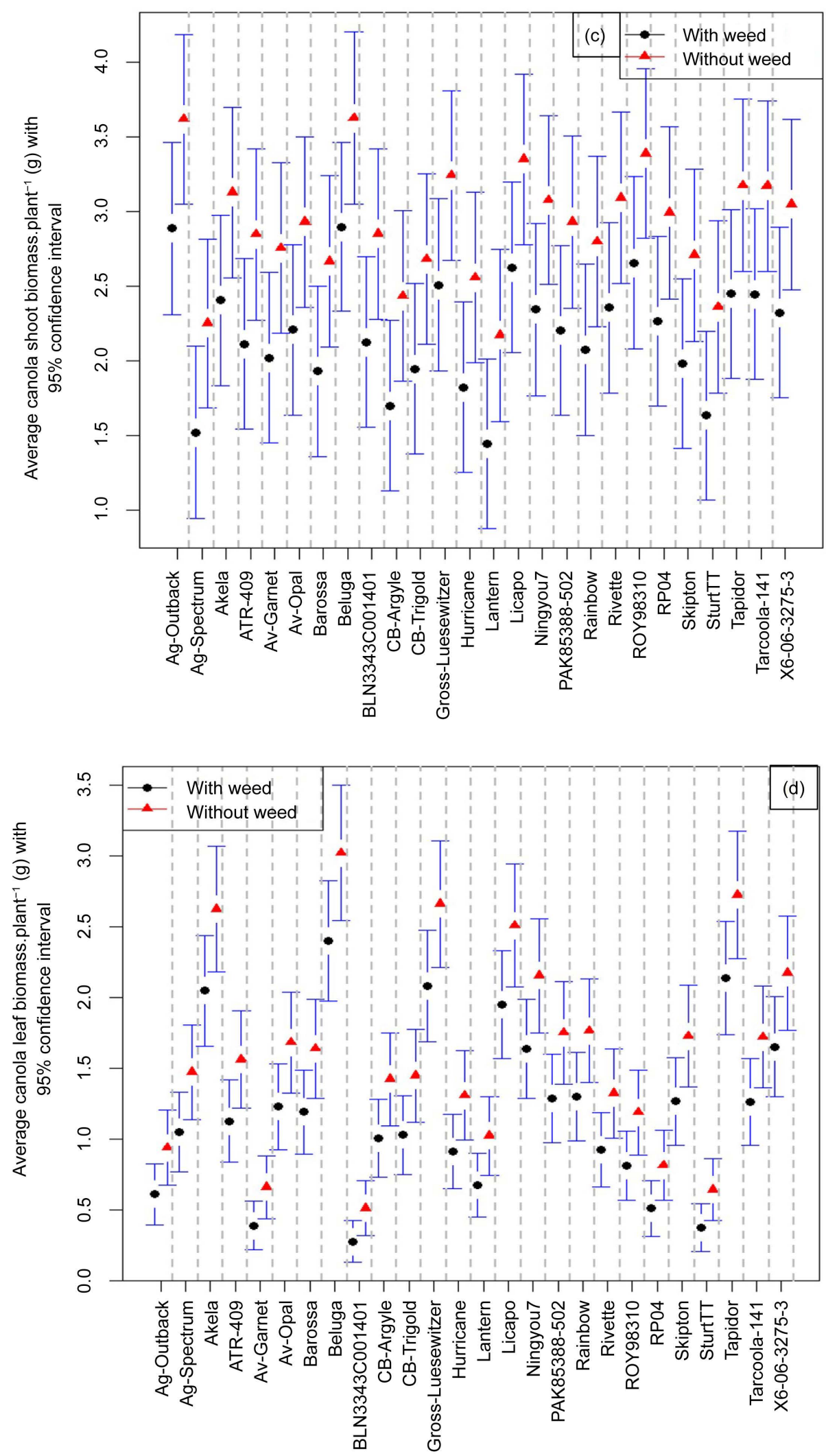

Figure 1. Weed competitiveness of the 26 canola genotypes against ryegrass. Predicted means from the fitted model described in Table 1 are presented: (a) weed biomass (g plant ${ }^{-1}$ ), (b) crop height $\left(\mathrm{cm}\right.$ plant $\left.{ }^{-1}\right),(\mathrm{c})$ crop biomass $\left(\mathrm{g} \mathrm{plant}^{-1}\right)$ and $(\mathrm{d})$ leaf biomass $\left(\mathrm{g} \mathrm{plant}^{-1}\right)$, as predicted. 

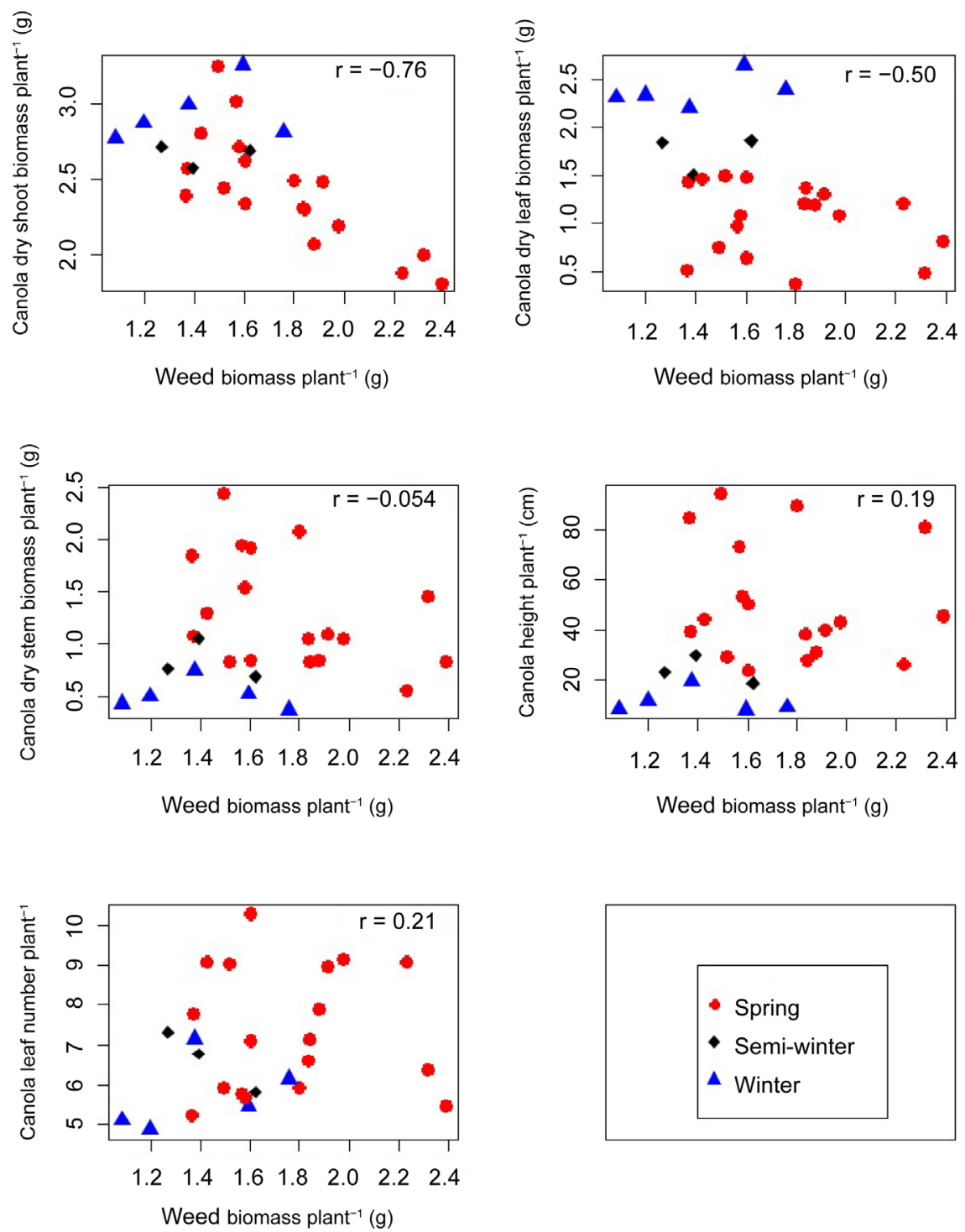

Figure 2. Correlation and correlation coefficient $(r)$ of five traits (dry shoot biomass, dry leaf biomass, dry stem biomass, plant height and leaf number) for 26 canola genotypes and of biomass for annual ryegrass under the glasshouse condition.

higher leaf and shoot biomass control ryegrass better as compared to less vigorous genotypes. In order to validate the competitiveness of vigorous varieties against ryegrass, we conducted a field experiment using 26 canola genotypes. Results reconfirmed that plant vigour (shoot biomass) is a genetic trait and significantly affects ryegrass (shoot biomass), but the interaction between genotypes and weed biomass was non-significant (Table 3). This indicates that genotype and/or weed treatment is not influenced with growing environment (ryegrass influenced the crop biomass at a constant rate across all genotypes). As observed under glasshouse experiment, there were significant genotypic differences in plant height; however it did not significantly affect ryegrass (shoot biomass). The interaction between genotypes and weed biomass was also significant 
Table 3. $P$-values for fixed effects (genotype) and covariate (weed biomass $\mathrm{g} \mathrm{plot}^{-1}$ ) and interaction between genotype and weed biomass $\left(\mathrm{g} \mathrm{plot}^{-1}\right)$, crop biomass $\left(\mathrm{g} \mathrm{plot}^{-1}\right)$, crop height $\left(\mathrm{cm} \mathrm{plant}^{-1}\right)$ at flowering (growth stage 65 , height 1 ) and physiological maturity (growth stage 80, height 2), measured under the field conditions.

\begin{tabular}{cccc}
\hline Effect & $\begin{array}{c}\text { Crop biomass } \\
\left(\mathrm{g} \mathrm{plot}^{-1}\right)^{*}\end{array}$ & $\begin{array}{c}\text { Crop height 1 } \\
\left(\mathrm{cm} \mathrm{plant}^{-1}\right)^{*}\end{array}$ & $\begin{array}{c}\text { Grain yield } \\
\left(\mathrm{g} \mathrm{plot}^{-1}\right)^{*}\end{array}$ \\
\hline Genotypes & $<0.001$ & $<0.001$ & $<0.001$ \\
Weed biomass $\left(\mathrm{g} \mathrm{plot}^{-1}\right)$ & 0.005 & 0.368 & 0.244 \\
Interaction & 0.132 & $<0.001$ & $\mathrm{n} / \mathrm{a}$ \\
Crop biomass $\left(\mathrm{g} \mathrm{plot}^{-1}\right)$ & $\mathrm{n} / \mathrm{a}$ & $\mathrm{n} / \mathrm{a}$ & $<0.001$ \\
Crop height 1 $\left(\mathrm{cm} \mathrm{plant}^{-1}\right)$ & $\mathrm{n} / \mathrm{a}$ & $\mathrm{n} / \mathrm{a}$ & 0.02 \\
Crop height 2 $\left(\mathrm{cm} \mathrm{plant}^{-1}\right)$ & $\mathrm{n} / \mathrm{a}$ & $\mathrm{n} / \mathrm{a}$ & $<0.001$ \\
Flowering time & $\mathrm{n} / \mathrm{a}$ & $\mathrm{n} / \mathrm{a}$ & 0.159 \\
\hline
\end{tabular}

${ }^{*} \mathrm{n} / \mathrm{a}$, Not applicable, covariate included in the analysis.

(Table 3). The main effect of genotypes on grain yield was highly significant, whereas the effects of weed biomass and flowering time were not significant. The significant genetic effects of crop biomass and plant height may have accounted the variation in yield (Table 3 ).

\subsection{Correlation between Weed Biomass, and Canola Development and Productivity Traits under Field Conditions}

Crop biomass and grain yield showed significantly negative correlations with ryegrass biomass. As anticipated, crop biomass was strongly correlated $(r=0.55)$ with grain yield (Figure 3). Four canola genotypes: Ag-Outback, Av-Opal, Skipton and X6-06-3275-3 showed the higher dry biomass, indicating that these genotypes have strong ability for ryegrass competitiveness. These genotypes produced higher grain yield as compared to cvs. Ag-Spectrum, Beluga, CB-Argyle, Lantern and Tapidor that had the lower biomass and grain yield (Figure 4(a) and Figure 4(c)). Early flowering resulted in the increase of yield and showed a negative correlation (Figure 3). Crop height measured at both flowering and physiological stages was positively correlated with yield, with correlation coefficient 0.74 and 0.67 , respectively. Five canola genotypes, PAK85388-502, Rivette, Av-Garnet, Tarcoola-141 and X6-06-3275-3, were taller and those genotypes had the higher yields (Figure 4(b) and Figure 4(c)). However, ryegrass biomass was poorly correlated with crop height at the flowering and physiological maturity (Figure 3 ). Winter varieties were the shortest compared with semi-winter and spring varieties which could be attributed to their vernalisation requirement.

\subsection{Correlation between Weed Suppression Ability of Canola Genotypes under the Glasshouse and Field Conditions}

A positive relationship was observed between ryegrass and crop biomass data 


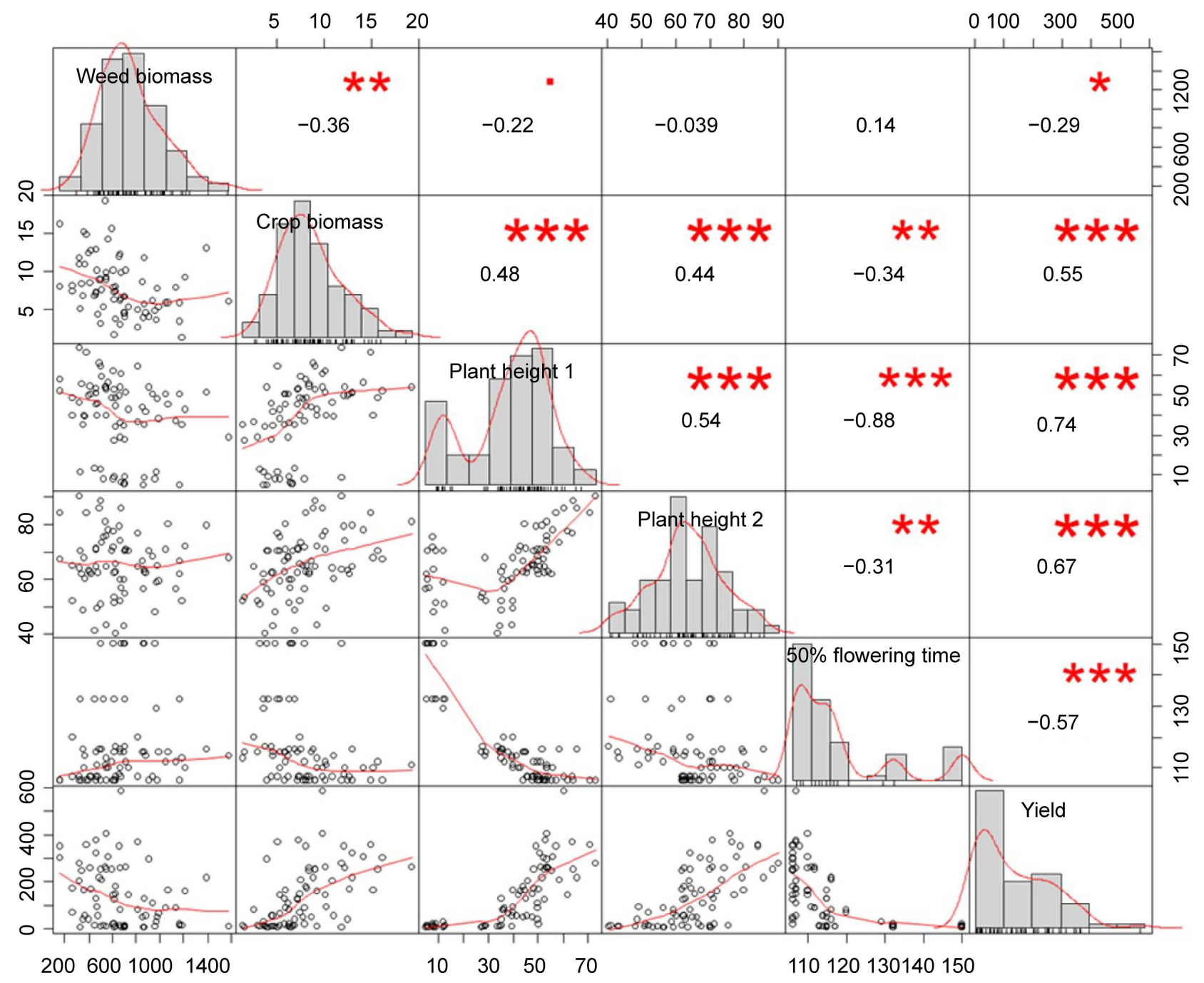

Figure 3. Correlation, correlation coefficient and normal distribution of five traits for 25 canola genotypes and of biomass for annual ryegrass grown under the field condition.

collected under glasshouse and field conditions (Figure 5). Our results showed that five canola genotypes: Akela, PAK85388-502, Av-Opal, Av-Garnet and Tarcoola-141 had lower weed biomass under both conditions, whereas Ag-Spectrum had the highest weed biomass. There was higher biomass of ryegrassin Lantern under the glasshouse condition but it was moderate under the field condition and this may have attributed to the variable density of ryegrass and require further verification.

\section{Discussion}

Weed biomass, crop height, crop biomass and yield are the common proxy traits used to screen canola genotypes for the weed-crop competition under field conditions. However, field-based screening has some limitations which influence the reliability and accuracy of phenotypic estimations. Screening different germplasm for weed-crop competition under glasshouse conditions can provide 

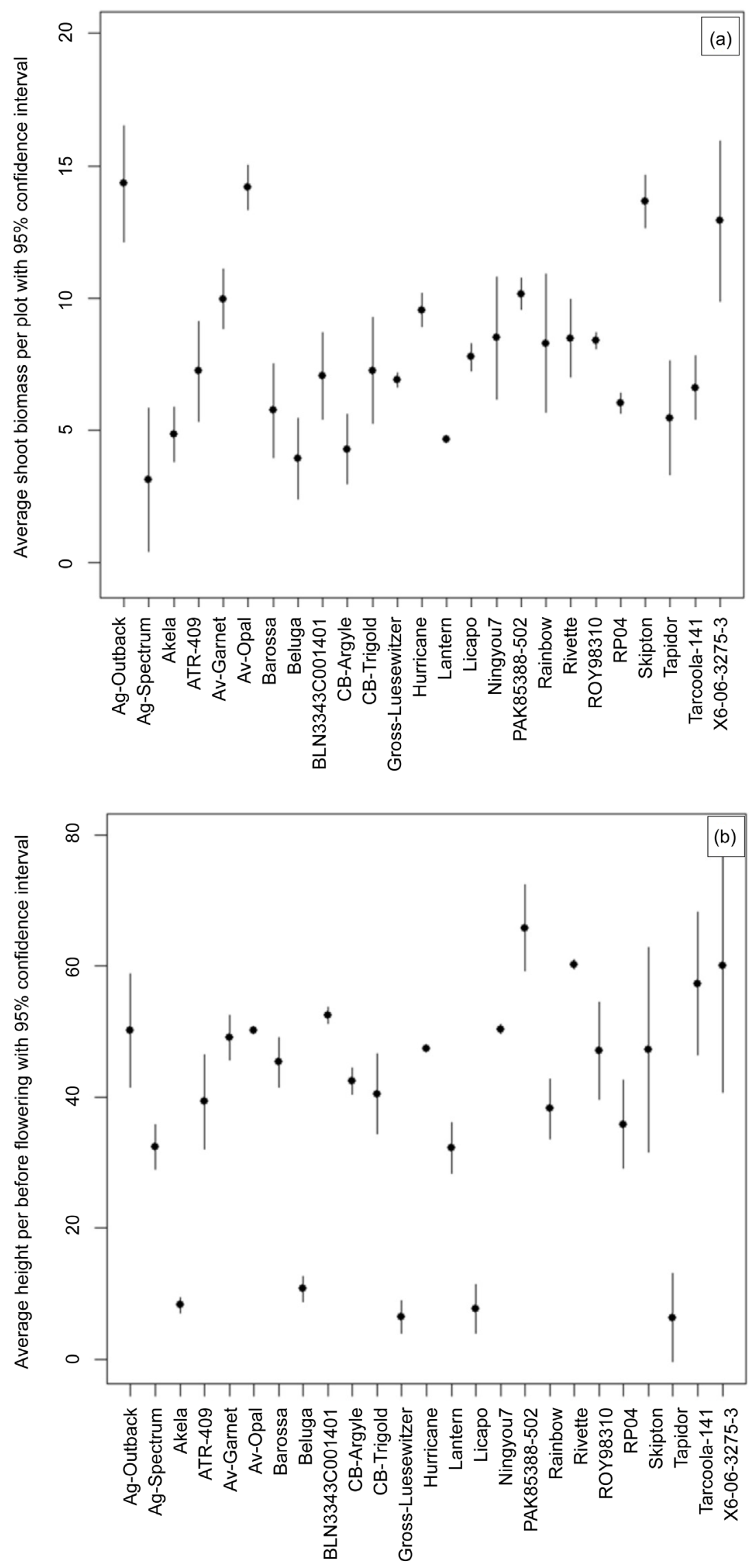


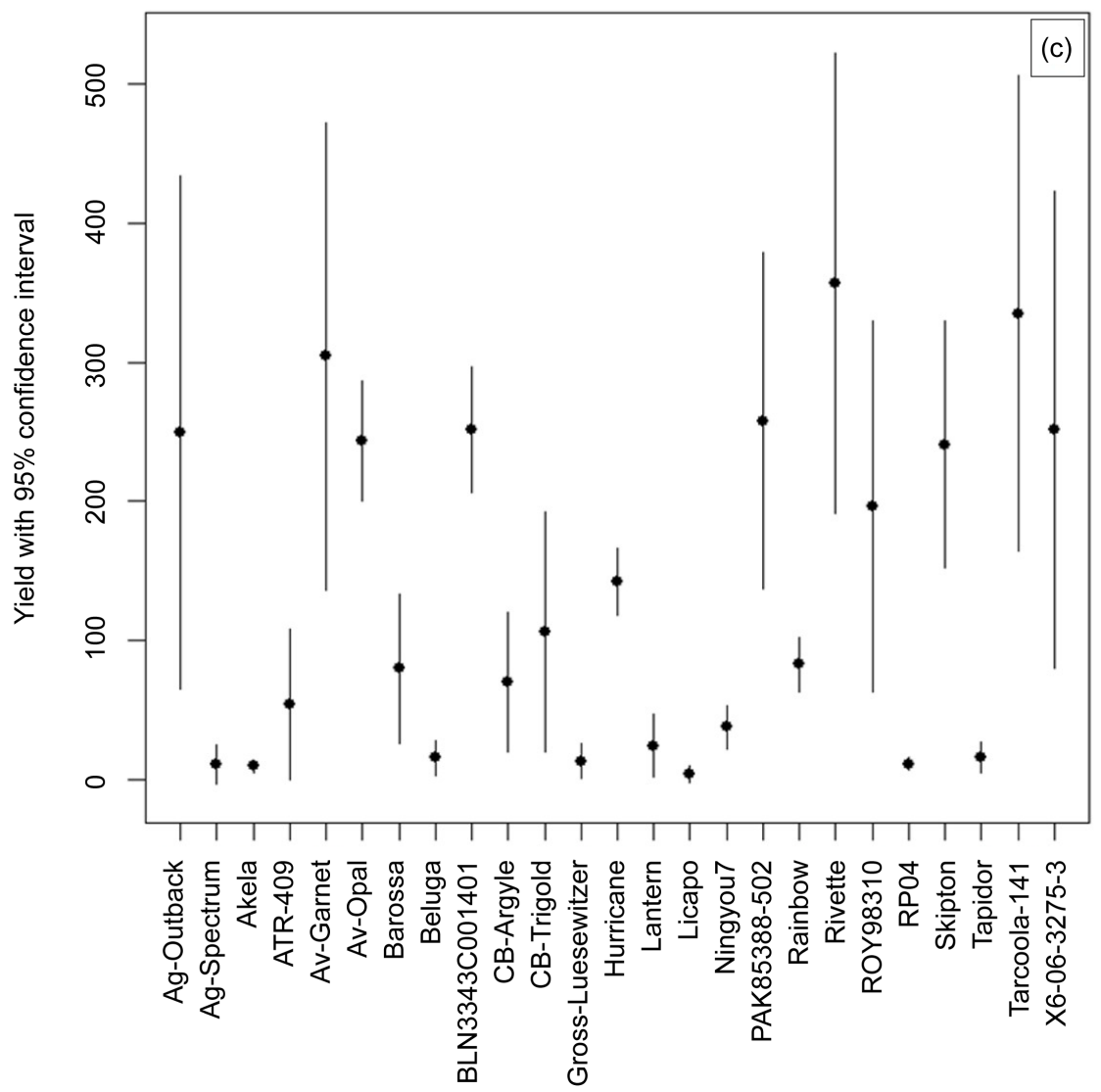

Figure 4. The 25 canola genotypes means with $95 \%$ confidence interval for: (a) crop biomass $\left(\mathrm{g} \mathrm{plot}^{-1}\right)$ as predicted from the fitted model: canola genotypes * weed biomass ( $\mathrm{g}$ plot $\left.^{-1}\right)$, (b) crop height at flowering stage $\left(\mathrm{cm} \mathrm{plant}^{-1}\right)$ as predicted from the fitted model: canola genotype ${ }^{\star}$ weed biomass $\left(\mathrm{g} \mathrm{plot}^{-1}\right)$, (c) grain yield $\left(\mathrm{g} \mathrm{plot}^{-1}\right)$ as predicted from the fitted model: canola genotypes + weed biomass $\left(\mathrm{g} \mathrm{plot}^{-1}\right)+$ crop biomass $\left(\mathrm{g} \mathrm{plot}^{-1}\right)+$ crop height at physiological stage $\left(\mathrm{cm} \mathrm{plant}^{-1}\right)+$ crop height at flowering stage $\left(\mathrm{cm} \mathrm{plant}^{-1}\right)+$ time to $50 \%$ flowering.

some advantages over field conditions. In our study we compared the competitiveability of 26 Brassica genotypes to suppress ryegrass under glasshouse and field conditions. For most traits, genotypes and weed treatments had a high significant effect. The interaction was only significant on crop height in both conditions. Five genotypes: Akela, Tarcoola-141, Av-Opal, Av-Garnet and PAK85388-502 consistently showed the ability to suppress weed ryegrass in both glasshouse and field conditions. Majority of these varieties had also the highest grain yields in the field conditions except in Akela.

A good understanding of morphology and phenology of both weed and crop could lead to an improvement in weed-crop competition via the use of genetic and genomic tools. In cereals, extensive leaf display, leaf area index, long flag leaves and good ground cover have been associated with superior competitive ability [31] [35] [36]. Morphological traits associated with the interception of radiation by leaves including plant height, leaf size, number and leaf area index, have been implicated in competiveness for light [26]. Our study showed a 


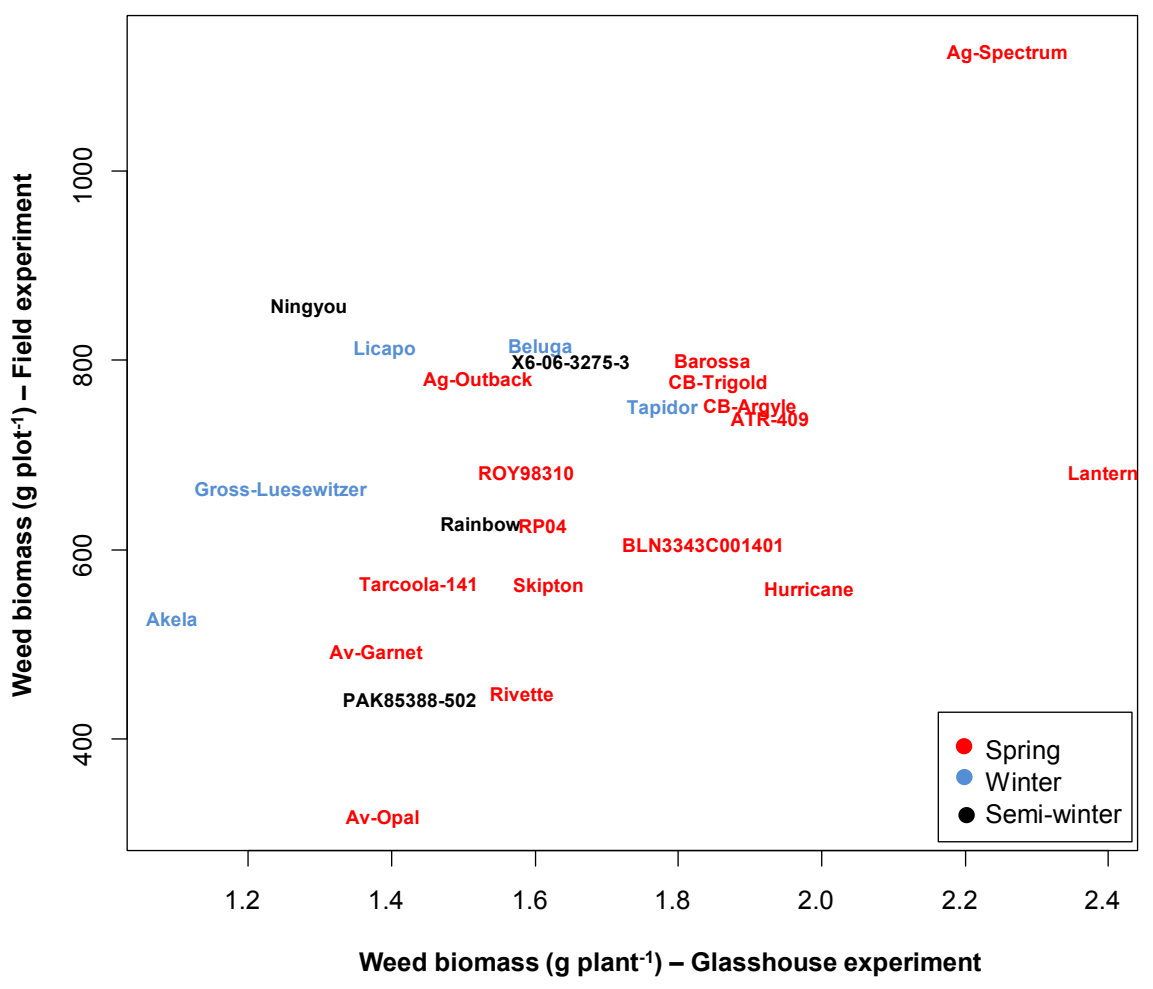

Figure 5. Correlation between two set of data of annual ryegrass biomass grown with 25 canola genotypes under the glasshouse and field conditions.

significant correlation between crop biomass and ryegrass suppression in both glasshouse and field conditions. These results indicate that plant vigour, manifested in higher canola biomass is associated with suppression of annual ryegrass. This is in agreement with previous studies where diverse canola accessions were compared under field conditions and showed that early-season crop biomass accumulation (early vigour) was associated with weed suppression [16] [17] [22]. In the glasshouse experiment, we found that leaf biomass was significantly correlated with weed suppression $(r=-0.50)$, whereas crop stem biomass did not show any correlation $(r=-0.05)$. Number of leaves also was not correlated with weed suppression. These results indicate that larger leaves are likely to provide shade and thus interfere with light inception to ryegrass. Further studies to understand the association between the area and angle of leaves and the suppression of weed growth are required for the germplasm used in our study. This would identify effective phenotypic traits for weed competition in a breeding program. Under field conditions, increase in crop biomass was associated with reductions in ryegrass biomass and with increased crop yields. This may reveal that canola biomass and particularly leaf biomass related to weed suppression and consequently improvement in yield.

The glasshouse and field experiments showed a low correlation between crop height and weed suppression but no correlation between crop stem biomass and weed suppression. Such lack of relationship has also been found in screening 111 rice genotypes against Echinochloa crus-galli in the field [37]. However, this re- 
sult is not in agreement with previous studies in canola. The glasshouse experiment (Figure 1(b)) indicated that crop height was less affected by the presence of weed compared with those in weed free conditions, whereas crop biomass was highly affected by weed (Figure 1(c)). Similarly, in the field experiment, crop height was not significantly influenced by the weed, whereas the crop biomass was. Most winter varieties found in our study are good weed suppressors in the glasshouse experiment (Figure 1(a)) and only Akela was superior in weed suppression in the field experiment (Figure 4). A spring genotype, Tarcoola-141 showed better ability in weed suppression under the glasshouse and field conditions with higher yield in the field. Other two spring genotypes, Av-Opal and Av-Garnet and a semi-winter PAK85388-502 demonstrated good weed suppression under both conditions as it was found in other studies [9] [17]. Three spring genotypes including Ag-Spectrum, Lantern and Sturt-TT were found less to be weed suppressive under glasshouse and field conditions and had low grain yield in the presence of weeds.

\section{Conclusion}

Our study suggests that: 1) vigorous canola varieties can provide competitiveness to ryegrass under glasshouse and field conditions and 2) glasshouse conditions can be used to evaluate weed suppression ability of a large number of canola accessions while maintaining uniform density of annual ryegrass. We conclude that vigorous genotypes with highest weed suppression can be exploited for weed control in canola. Further research is required to develop structured populations between highest and lowest weed suppression genotypes can be developed to understand genetics underlying this valuable trait. Molecular markers can be developed for marker assisted selection leading to an acceleration of improved varietal development pipeline.

\section{Acknowledgements}

Authors are thankful to NSW Department of Primary Industries for supporting this research.

\section{Conflicts of Interest}

The authors declare no conflicts of interest regarding the publication of this paper.

\section{References}

[1] AOF (2017) Australian Oilseeds Federation. Crop Report. http://www.australianoilseeds.com/_data/assets/pdf_file/0012/11190/AOF_Crop_ Report_July_2017.pdf

[2] Lemerle, D., Blackshaw, R., Smith, A., Potter, T. and Marcroft, S. (2001) Comparative Survey of Weeds Surviving in Triazine-Tolerance and Conventional Canola Crops in South-Eastern Australia. Plant Protection Quarterly, 16, 37-40.

[3] Llewellyn, R.R.D., Ouzman, J., Walker, S., Mayfield, A. and Clarke, M. (2016) Im- 
pact of Weeds on Australian Grain Production: The Cost of Weeds to Australian Grain Growers and the Adoption of Weed Management and Tillage Practices. Report to GRDC and CSIRO, Australia.

[4] Broster, J., Pratley, J., Ip, R., Ang, L. and Seng, K. (2019) A Quarter of a Century of Monitoring Herbicide Resistance in Lolium rigidum in Australia. Crop and Pasture Science, 70, 283-293. https://doi.org/10.1071/CP18584

[5] Heap, I. (2017) The International Survey of Herbicide Resistant Weeds. http://www.weedscience.org

[6] Donald, C. (1963) Competition among Crop and Pasture Plants. In: Norman, A.G., Ed., Advances in Agronomy, Volume 15, Academic Press, New York, 1-118. https://doi.org/10.1016/S0065-2113(08)60397-1

[7] Pratley, J.E. (1996) Allelopathy in Annual Grasses. Plant Protection Quarterly, 11, 213-214.

[8] Asaduzzaman, M., An, M., Pratley, J.E., Luckett, D.J. and Lemerle, D. (2014) Canola (Brassica napus) Germplasm Shows Variable Allelopathic Effects against Annual Ryegrass (Lolium rigidum). Plant Soil, 380, 47-56.

https://doi.org/10.1007/s11104-014-2054-4

[9] Asaduzzaman, M., Luckett, D., Cowley, R., An, M. and Pratley, J. (2014) Canola Cultivar Performance in Weed-Infested Field Plots Confirms Allelopathy Ranking from in Vitro Testing. Biocontrol Science and Technology, 24, 1394-1411.

https://doi.org/10.1080/09583157.2014.942596

[10] Bais, H.P., Weir, T.L., Perry, L.G., Gilroy, S. and Vivanco, J.M. (2006) The Role of Root Exudates in Rhizosphere Interactions with Plants and Other Organisms. Annual Review of Plant Biology, 57, 233-266. https://doi.org/10.1146/annurev.arplant.57.032905.105159

[11] Lemerle, D., Verbeek, B., Cousens, R.D. and Coombes, N.E. (1996) The Potential for Selecting Wheat Varieties Strongly Competitive against Weeds. Weed Research, 36, 505-513. https://doi.org/10.1111/j.1365-3180.1996.tb01679.x

[12] Asaduzzaman, M., Luckett, D.J., An, M., Pratley, J.E. and Lemerle, D. (2014) Management of Paterson's Curse (Echium plantagineum) through Canola Interference. In: Nineteenth Australasian Weeds Conference, Hobart, 162-165.

[13] Seal, A.N. and Pratley, J.E. (2010) The Specificity of Allelopathy in Rice (Oryza sativa). Weed Research, 50, 303. https://doi.org/10.1111/j.1365-3180.2010.00783.x

[14] Wu, H., Pratley, J.E., Lemerle, D. and Haig, T. (2000) Laboratory Screening for Allelopathic Potential of Wheat (Triticum aestivum) Accessions against Annual Ryegrass (Lolium rigidum). Australian Journal of Agricultural Research, 51, 259-266. https://doi.org/10.1071/AR98183

[15] Asaduzzaman, M., Pratley, J.E., Min, A., Luckett, D.J. and Lemerle, D. (2014) Canola Interference for Weed Control. Science Reviews, 2, 63-74. https://doi.org/10.1007/s40362-014-0022-2

[16] Daugovish, O., Thill, D. and Shafii, B. (2002) Competition between Wild Oat (Avena fatua) and Yellow Mustard (Sinapis alba) or Canola (Brassica napus). Weed Science, 50, 587-594. https://doi.org/10.1614/0043-1745(2002)050[0587:CBWOAF]2.0.CO;2

[17] Lemerle, D., Luckett, D., Lockley, P., Koetz, E. and Wu, H. (2014) Competitive Ability of Australian Canola (Brassica napus) Genotypes for Weed Management. Crop and Pasture Science, 65, 1300-1310. https://doi.org/10.1071/CP14125

[18] Raman, H., Shamaya, N. and Pratley, J. (2018) Genetic Variation for Weed Compe- 
tition and Allelopathy in Rapeseed (Brassica napus L.). In: Radhakrishnan, R., Ed., Biological Approaches for Controlling Weeds, IntechOpen, London, United Kingdom. https://doi.org/10.5772/intechopen.79599

[19] Lutman, P.J.W., Dixon, F.L. and Risiott, R. (1994) The Response of Four Spring-Sown Combination Arable Crops to Weed Competition. Weed Research, 34, 137-146. https://doi.org/10.1111/j.1365-3180.1994.tb01981.x

[20] Melander, B. (1993) Modelling the Effects of Elymus repens (L.) Gould Competition on Yield of Cereal, Peas and Oilseed Rape. Weed Research, 33, 99-108. https://doi.org/10.1111/j.1365-3180.1994.tb01977.x

[21] Lemerle, D.V. and Coombes, N.E. (1995) Losses in Grain Yield of Winter Crops from Lolium rigidum (Gaud.) Depend on Crop Species, Cultivar and Season. Weed Research, 35, 503-509. https://doi.org/10.1111/j.1365-3180.1995.tb01648.x

[22] Beckie, H.J., Johnson, E.N., Blackshaw, R.E. and Gan, Y. (2008) Weed Suppression by Canola and Mustard Cultivars. Weed Technology, 22, 182-185. https://doi.org/10.1614/WT-07-126.1

[23] Harker, N.C., Blackshaw, R. and O’Donovan, J. (2003) Seeding Rate, Herbicide Timing and Competitive Hybrids Contribute to Integrated Weed Management in Canola (Brassica napus). Canadian Journal of Plant Science, 83, 433-440. https://doi.org/10.4141/P02-073

[24] Harker, N., O’Donovan, J., Blackshaw, R., Johnson, E., Holm, F. and Clayton, G. (2011) Environmental Effects on the Relative Competitive Ability of Canola and Small-Grain Cereals in a Direct-Seeded System. Weed Science, 59, 404-415. https://doi.org/10.1614/WS-D-10-00121.1

[25] Lemerle, D., Lockley, P., Koetz, E. and Wu, H. (2014) Competitive Ability of Australian Canola (Brassica napus) Genotypes for Weed Management. Crop and Pasture Science, 65, 1300-1310. https://doi.org/10.1071/CP14125

[26] Coleman, R., Gill, G. and Rebetzke, G.J. (2001) Identification of Quantitative Trait Loci for Traits Conferring Weed Competitiveness in Wheat (Triticum aestivum L.). Australian Journal of Agricultural and Research, 52, 1235-1246. https://doi.org/10.1071/AR01055

[27] Asaduzzaman, M., An, M., Pratley, J.E., Luckett, D.J. and Lemerle, D. (2014) Laboratory Bioassay for Canola (Brassica napus) Allelopathy. Journal of Crop Science and Biotechnology, 17, 267-272. https://doi.org/10.1007/s12892-014-0087-0

[28] Zand, E. and Beckie, J. (2002) Competitive Ability of Hybrid and Open-Pollinated Canola (Brassica napus) with Wild Oat (Avena fatua). Canadian Journal of Plant Science, 82, 473-480. https://doi.org/10.4141/P01-149

[29] Worthington, M. and Reberg-Horton, C. (2013) Breeding Cereal Crops for Enhanced Weed Suppression: Optimizing Allelopathy and Competitive Ability. Journal of Chemical Ecology, 39, 213-231. https://doi.org/10.1007/s10886-013-0247-6

[30] Gealy, D.R. and Yan, W. (2012) Weed Suppression Potential of 'Rondo' and Other Indica Rice Germplasm Lines. Weed Technology, 26, 517-524.

https://doi.org/10.1614/WT-D-11-00141.1

[31] Johnson, D.E., Dingkuhn, M., Jone, M.P. and Mahamane, M.C. (1998) The Influence of Rice Plant Type on the Effect of Weed Competition on Oryza sativa and Oryza glaberrima. Weed Research, 38, 207-216. https://doi.org/10.1046/j.1365-3180.1998.00092.x

[32] Team, R.D.C. (2014) R: A Language and Environment for Statistical Computing. R Foundation for Statistical Computing, Vienna, Austria. http://www.R-project.org/

[33] Butler, D.G., Cullis, B.R., Gilmour, A.R. and Gogel, B.J. (2009) ASReml-R Reference 
Manual. Release 3.0. Technical Report, Queensland Department of Primary Industries, Australia. http://www.vsni.co.uk/downloads/asreml/release2/doc/asreml-R.pdf

[34] Sarkar, D. (2008) Lattice: Multivariate Data Visualization with R. Springer, New York. https://doi.org/10.1007/978-0-387-75969-2

[35] Donald, C.M. and Hamblin, J. (1976) Biological Yield and Harvest Index of Cereal as Agronomic and Plant Breeding Criteria. Advances in Agronomy, 28, 361-405. https://doi.org/10.1016/S0065-2113(08)60559-3

[36] Huel, D.G. and Hucl, P. (1996) Genotypic Variation for Competitive Ability in Spring Wheat. Plant Breeding, 115, 325-329. https://doi.org/10.1111/j.1439-0523.1996.tb00927.x

[37] Olofsdotter, M., Navarez, D., Rebulanan, M. and Streibig, J. (1999) Weed-Suppressing Rice Cultivars: Does Allelopathy Play a Role? Weed Research, 39, 441-454. https://doi.org/10.1046/j.1365-3180.1999.00159.x 